\title{
Avaliação corneana após 'crosslink' utilizando dois tipos diferentes equipamentos
}

\author{
Corneal assessment after using two different \\ types of crosslinking equipment
}

Edna Motta Almodin', Juliana Motta Almodin², Flavia Motta Almodin ${ }^{3}$

\section{RESUMO}

Objetivo: Avaliação corneana pós-operatória com a utilização de crosslinking com dois equipamentos distintos. Métodos: Dois grupos de pacientes: grupo A com 36 olhos e grupo B com 19 olhos foram submetidos ao tratamento por crosslinking de colágeno corneano para estabilização de ceratocone. No grupo A foi utilizado o equipamento Crosslink (IROC - Alemanha) e no grupo B o equipamento X-link (Opto - Brasil). Resultados: Foi avaliado o tempo de reepitelização corneana, acuidade visual, biomicroscopia, topografia, tomografia corneana e microscopia especular após uma semana, 1 mês, 3 meses e 1 ano após os procedimentos cirúrgicos. Não houve diferença significativa na avaliação entre os dois grupos. Conclusão: O resultado pós-operatório nos dois grupos foi semelhante.

Descritores: Ceratocone/cirurgia; Reagentes para ligações cruzadas; Riboflavina; Raios ultravioleta; Colágeno

${ }^{1}$ Médica e Diretora do Provisão Hospital de Olhos de Maringá - Maringá (PR), Brasil;

${ }^{2}$ Médica do Provisão Hospital de Olhos de Maringá - Maringá (PR), Brasil;

${ }^{3}$ Médica Estagiária do Instituto de Olhos Tadeu Cvintal - São Paulo (SP), Brasil;

O trabalho foi realizado no Provisão Hospital de Olhos de Maringá - Maringá (PR), Brasil.

Recebido para publicação em: 26/11/2009 - Aceito para publicação em 6/4/2010 


\section{INTRODUÇÃO}

$\mathbf{O}$ ceratocone é uma doença corneana progressiva que frequentemente aparece na adolescência e na qual a córnea se afina e muda sua forma. A córnea normalmente é arredondada ou esférica, mas com o ceratocone, sofre uma protuberância que distorce e assume a forma de um cone. Isto afeta a maneira com que a luz entra no olho e chega à retina, alterando e distorcendo a visão( ${ }^{(1)}$. O tratamento do ceratocone tem sido a utilização de lentes corretoras e nos casos avançados, transplante de córnea. Mais recentemente tem sido utilizado com sucesso o implante de anel intraestromal ${ }^{(2,3)}$. Alguns autores têm estudado a redução na trama cruzada do colágeno (crosslinking) corneano relacionando aos níveis anormais de dehidronorleucina, provavelmente devido a mudanças na hidroxilação de resíduos de lysyl de colágeno normal ou síntese de colágeno anormal ${ }^{(4)}$. O estudo biomecânico da córnea e sua capacidade de se alterar com modificações bioquímicas e biofísicas já vêm sendo estudados desde a década de 70. A comprovação destas modificações tem sido estruturada nas possíveis alterações do colágeno. Estas alterações do colágeno fazem com que a córnea fique mais propensa às degenerações e alterações que propiciam o abaulamento corneano, causando assim o ceratocone ${ }^{(4)}$. Atualmente tem sido relatado a exposição corneana à ação de Riboflavina sob a irradiação de raios ultravioleta com a finalidade de causar enrijecimento corneano e se disponibilizando como forma alternativa de tratamento para ceratocone ${ }^{(5,6)}$.

O objetivo deste trabalho é avaliar o resultado corneano pós-tratamento por crosslinking utilizando dois equipamentos distintos.

\section{Métodos}

Após aprovação pelo comitê em ética e pesquisa do Hospital Almodin Ltda., dois grupos de pacientes para este estudo prospectivo foram avaliados, sendo grupo A com 36 olhos e grupo B com 19 olhos. Esses pacientes foram submetidos ao tratamento por crosslinking de colágeno corneano para estabilização de ceratocone. No grupo A foi utilizado o equipamento Crosslink (IROC® - Alemanha) e no grupo B o equipamento X-link (Opto Brasil $\left.{ }^{\circledR}\right)$. Em ambos os grupos os pacientes tinham entre 22 e 38 anos de idade, sendo que no grupo A 18 pacientes eram masculinos e 18 femininos e no grupo B 11 eram masculinos e 8 eram femininos. Os casos excluídos do presente estudo foram pacientes que apresentavam ceratocone avançado com estrias, leucomas ou espessuras corneanas menores de $400 \mathrm{M}$.

Os procedimentos foram realizados após ciência do termo de consentimento livre e esclarecido. Os procedimentos foram efetuados em ambiente cirúrgico, com utilização de assepsia e antissepsia com povidine. Foi realizado abrasão corneana no diâmetro de $9 \mathrm{~mm}$, com utilização de colírio anestésico (Allergan ${ }^{\circledR}$-Brasil) e lâmina de bisturi $\mathrm{n}^{\circ}$ 10, aplicação de Riboflavina $0.1 \%$ em $20 \%$ de dextran (IROC®- Alemanha) de 5/5minutos intercalados com solução salina balanceada (BSSAlcon ${ }^{\circledR}$, Brasil) até que a câmera anterior estivesse colorida de amarelo (30 minutos). A seguir, aplicação de ultravioleta (UV- Grupo A com Crosslink - Iroc Alemanha e Grupo B com X-link - Opto Brasil) - com 365nm, $3 \mathrm{mw}$ por 30 minutos. Durante a aplicação de UV era ministrado Riboflavina na mesma concentração, de 5/ 5minutos intercalada com BSS. Ou seja, 2,5 minutos após aplicação da Riboflavina era gotejado o BSS e 2,5 minutos após, novamente a Riboflavina e assim sucessivamente por 30 minutos. Após finalizado o procedimento era colocado uma lente de contato (Focus Monthly - Ciba Vision-Brasil®). Na liberação era prescrito Gatifloxacino $0.3 \%$ de $6 / 6 \mathrm{~h}$ por 1 semana, Predinisolona $12 /$ $12 \mathrm{~h}$, lubrificante - ácido polivinílico $1.4 \%$ de $6 / 6 \mathrm{~h}$ por 30 dias e analgésico oral fosfato de codeína $7.5 \mathrm{mg}$ 12/12h por 5 dias. A Prednisolona era mantida até a reepitelização corneana e após a mesma, era aumentado para 6/6 h por mais 3 semanas, $\mathrm{O}$ acompanhamento pós-operatório foi realizado através da avaliação com lâmpada de fenda, medida de acuidade visual, microscopia especular, topografia corneana e refração. A avaliação pósoperatória foi realizada com 24 h, 8 dias , 30 dias, 6 meses e 1 ano. A avaliação de 24 h foi somente clínica e as demais avaliações foram clínica e mensurações.

\section{Resultados}

Analisamos o resultado de 55 olhos operados entre setembro de 2006 a dezembro de 2007, que tinham seguimento por até 1 ano. Os pacientes foram examinados com 24h, 1 semana, 1 mês, 3 meses, 6 meses e 1 ano. Os exames para avaliação de resultados foram: biomicroscopia, medida de acuidade visual, refração, microscopia especular, e topografia corneana.

$\mathrm{Na}$ biomicroscopia foi avaliado o tempo de reepitelização para retirada da lente de contato e a presença ou não de haze.

A reepitelização ocorreu entre 3 a 45 dias, sendo que a média foi de 10 dias com o aparelho IROC e 13 

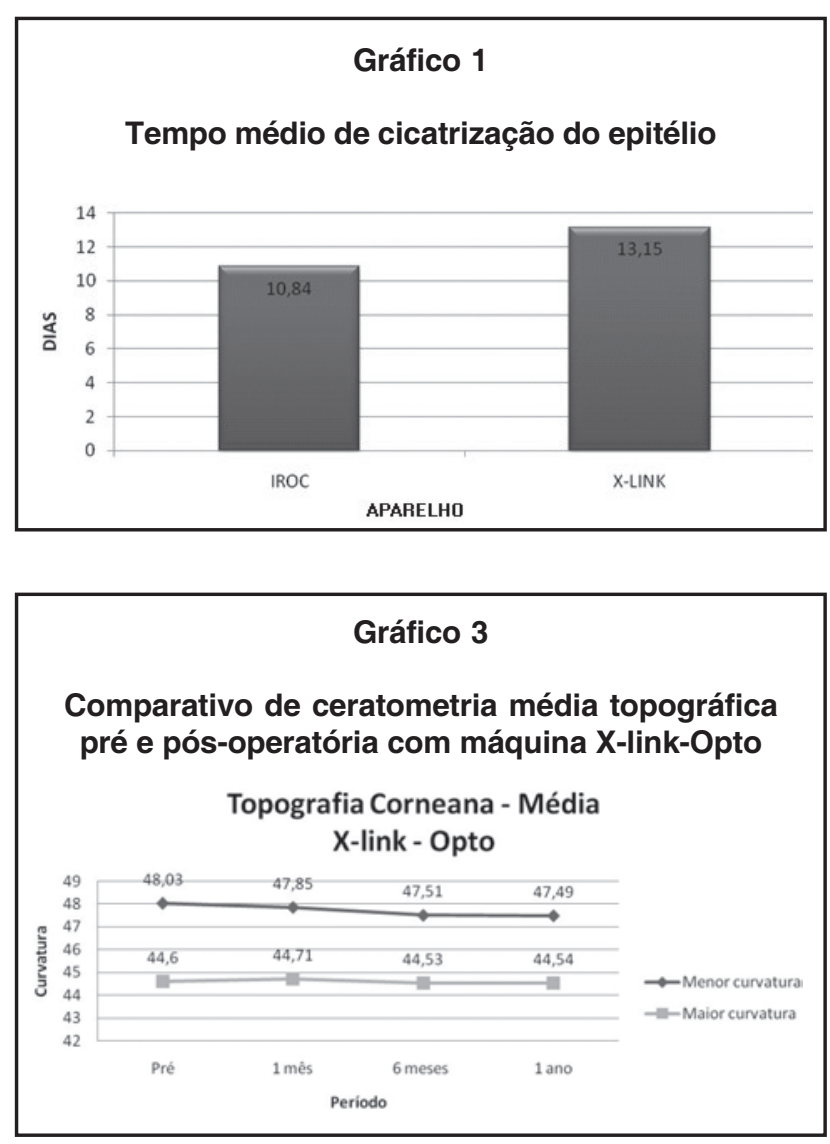

dias com o X-link Opto (gráfico 1).

Nos 2 grupos, a acuidade visual destes pacientes mostrou piora no primeiro mês, voltando ao estágio inicial ou com melhora de uma a duas linhas de visão no sexto mês, conforme mostram as tabelas 1 e 2

A refração média em equivalente esférico também não apresentou melhora significativa. A refração em equivalente esférico piora no primeiro mês e volta ao valor pré-operatório ou com melhora média de 0.5 dioptria, em 6 meses (tabelas 3 e 4).

A média de ceratometria topográfica também não mostra melhora significativa de aplanamento na curvatura máxima. O gráfico demonstra a diminuição de apenas uma dioptria na curvatura corneana em 6 meses e no IROC houve até um aumento de uma e meia dioptria na curvatura máxima no primeiro mês de pós-operatório, sendo que em 6 meses estava igual ou 1 dioptria menor que o valor inicial de pré-operatório (gráficos 2 e 3 ).

O haze $1+/ 4+$ esteve presente em todos os casos, sendo que desapareceu nos primeiros 30 dias e 13\% (7 olhos) apresentaram haze $2+/ 4+$ a $3+/ 4+$, sendo que o mais duradouro desapareceu com o uso de corticóide, voltando à visão inicial. A máquina IROC foi responsável por $7 \%$ destes casos e o X-link Opto 6\%.Apenas um
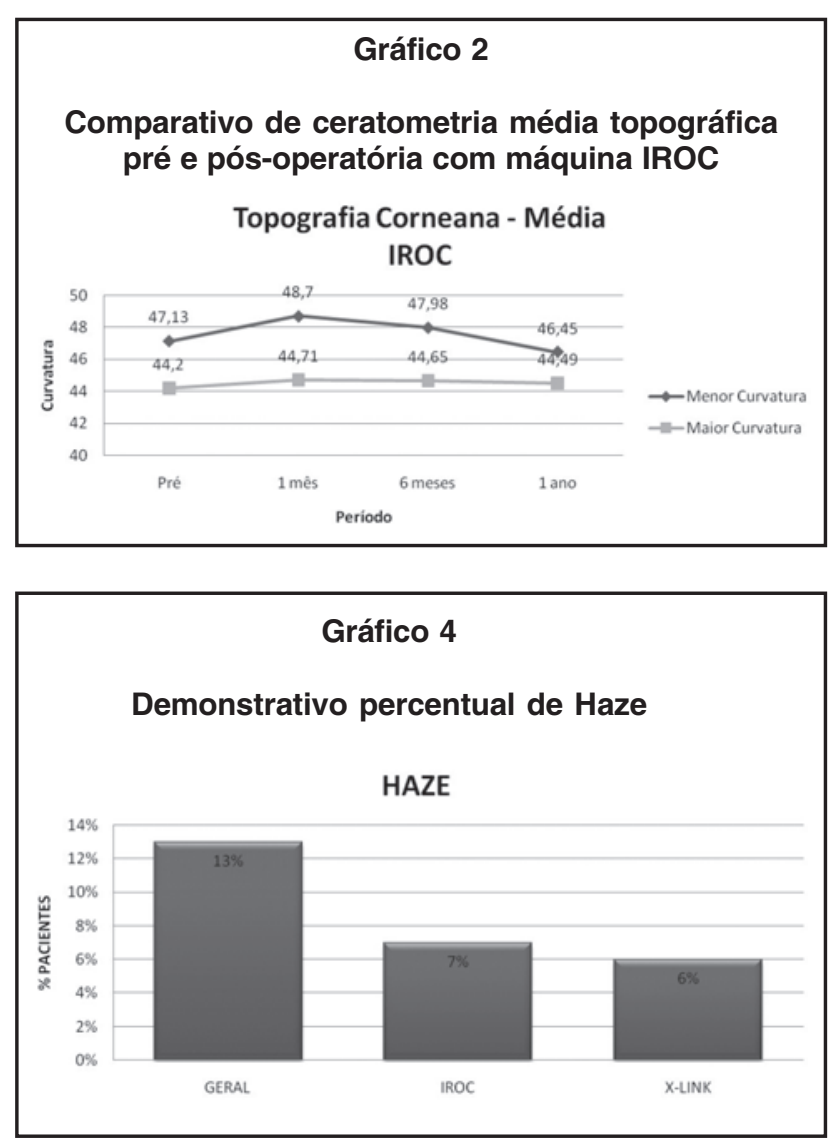

olho (1.8\%) permaneceu com baixa de 3 linhas de visão em comparação com o pré-operatório por mais de 6 meses, decorrente do haze (gráfico 4).

A microscopia especular permanece igual ou com pequena diminuição de células endoteliais nos 2 grupos. Porém nossa máquina de microscopia especular é de contato e pode ter pequenos desvios de contagem celular aos exames. A diminuição é tão insignificante que consideramos contagem endotelial não alterada neste grupo em que respeitamos os 400 micras de espessura corneana, medida pela paquimetria (gráficos 5 e 6 ).

\section{Dıscussão}

O crosslink de colágeno corneano com Riboflavina e ultravioleta é um método de tratar ectasias progressivas e os parâmetros de tratamento atualmente aceitos induzem o crosslink de colágeno em 250 a 350 micras de profundidade no estroma anterior corneano ${ }^{(7)}$.

Relatos mais recentes têm demonstrado que esta associação provoca apoptose dos queratócitos, atingindo até 300 micras de profundidade na córnea ${ }^{(8)}$. Esta população de queratócitos é recomposta em até 


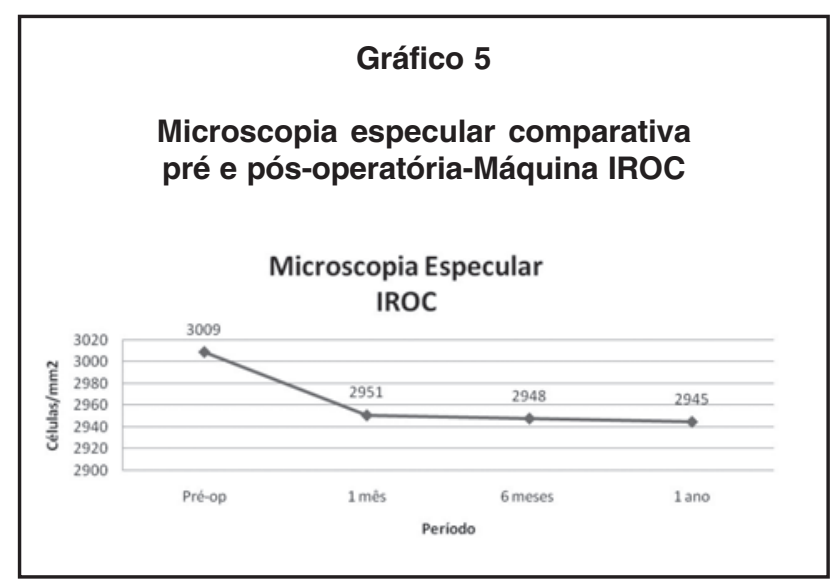

6 meses, e desde que se respeite o limite de 400 micras na espessura corneana não foi evidenciado danos ao endotélio, cristalino ou retina ${ }^{(9)}$. Pesquisadores têm demonstrado a utilização do crosslink em keratectasias após LASIK ${ }^{(10,11)}$. O recente alargamento das indicações na utilização desta nova metodologia tem sido utilizado no tratamento de úlceras corneanas, melting e ceratopatia bolhosa ${ }^{(10,12)}$.

Em 2006, Seiler et al. publicaram um artigo em que vinte e três olhos de 22 pacientes com ceratocone avançado (K máximo de 48-72D) foram estudados. Submeteram estes olhos a uma abrasão corneana central, gotas de riboflavina fotossensibilizadora foram aplicadas e depois os olhos foram expostos a UVA (370 $\mathrm{nm}, 3 \mathrm{~mW} / \mathrm{cm} 2 \mathrm{em} 1 \mathrm{~cm}$ de distância), durante 30 minutos. Foram executados exames pós-operatórios a cada 6 meses, incluindo medida de acuidade visual, topografia corneana, exame de lâmpada de fenda, medida da densidade de células endoteliais, e documentação fotográfica. O tempo de seguimento foi de 3 meses a 4 anos. Os resultados mostraram que em todos os olhos tratados houve parada da progressão do ceratocone. Em 16 olhos (70\%) houve regressão com diminuição na $\mathrm{K}$ máxima de $2.01 \mathrm{D}$ e do erro refrativo em 1.14 D. Córnea e cristalino transparentes, densidade de células endoteliais e pressão intraocular inalterados. A acuidade visual melhorou ligeiramente em 15 olhos $(65 \%)$ e ele concluiu que novos estudos precisavam ser efetuados, mas o crosslink de colágeno poderia ser um novo modo de parar a progressão da ectasia em ceratocone ${ }^{(13,14)}$. Em nosso estudo não houve nenhuma alteração significativa na microscopia especular destes pacientes, nos mostrando que respeitando as $400 \mu$ de espessura corneana, como relatado na literatura, não há lesão a nível de endotélio. Nossa experiência comprovou o

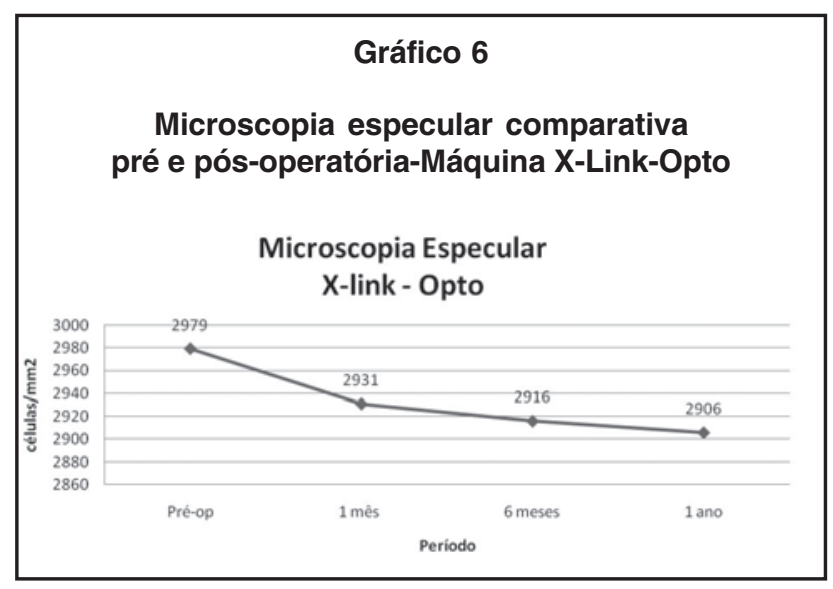

Tabela 1

IROC - Média de acuidade visual pré e pós-operatória

\begin{tabular}{lcccc}
\hline & Pré-operatório & $\mathbf{1}$ mês & $\mathbf{6}$ meses & $\mathbf{1 2}$ meses \\
\hline Média & $20 / 24.72$ & $20 / 27.50$ & $20 / 29.05$ & $20 / 23.33$ \\
DP & 0,36 & 0,23 & 0,16 & 0,20 \\
\hline
\end{tabular}

Tabela 2

X-Link OPTO - Média de acuidade visual pré e pós-operatória

\begin{tabular}{lcccc}
\hline & Pré-operatório & $\mathbf{1}$ mês & $\mathbf{6}$ meses & $\mathbf{1 2}$ meses \\
\hline Média & $20 / 25.26$ & $20 / 39.47$ & $20 / 20.52$ & $20 / 21.05$ \\
DP & 0,31 & 0,25 & 0,13 & 0,18 \\
\hline
\end{tabular}

Tabela 3

IROC - Refração em equivalente esférico e desvio padrão

\begin{tabular}{lcccc}
\hline & Pré-operatório & $\mathbf{1}$ mês & $\mathbf{6}$ meses & $\mathbf{1 2}$ meses \\
\hline Média & -2.89 & -3.00 & -2.93 & -2.81 \\
DP & 0,06 & 0,25 & 0,11 & 0,22 \\
\hline
\end{tabular}

Tabela 4

X-Link-OPTO - Refração em equivalente esférico e desvio padrão

\begin{tabular}{lcccc}
\hline & Pré-operatório & $\mathbf{1}$ mês & $\mathbf{6}$ meses & $\mathbf{1 2}$ meses \\
\hline Média & -2.17 & -2.18 & -2.02 & -2.03 \\
DP & 0,03 & 0,21 & 0,16 & 0,20 \\
\hline
\end{tabular}


efeito do crosslink estabilizando a ceratometria corneana topográfica e o crosslink pôde nos auxiliar, mostrando estabilidade da refração em um ano. Nenhuma alteração de cristalino ou retina foram observados nestes casos e nenhuma intercorrência per ou pós-operatória, portanto nenhum efeito adverso, o que nos mostra a segurança da técnica já descrita por vários autores.

Ceratite por Staphylococcus epidermidis ou Escherichia coli já foi confirmado como complicação de crosslink, que melhorou com uso de antibiótico fortificado, deixando astigmatismo residual significativo $(15,16)$. Caso de melting corneano após 5 dias de crosslink também já foi descrito. O raspado corneano foi positivo para Acanthamoeba ${ }^{(17)}$. Ceratite epitelial geográfica e iritis por herpes também já foram descritas como complicação nesta técnica. Crosslink pode induzir Ceratite herpética com iritis igual em pacientes sem história de doença herpética. Diagnóstico precoce e tratamento formal são essenciais para um resultado favorável.

Na nossa experiência não tivemos nenhum caso de infecção ou contaminação no pós-operatório e a avaliação pos-operatória revelou resultados semelhantes aos encontrados na literatura ${ }^{(18)}$.

\section{Conclusão}

Muito ainda temos que estudar em ceratocone, biomecânica e flexibilidade corneana. Estudos devem ser feitos para colocar os parâmetros de indicação e limites entre as duas técnicas, pois senão estaremos congelando córneas com refrações que podem ser melhoradas com o implante de anel. Faz-se necessário pesquisas para avaliar os limites do crosslink e do implante do anel. Cremos que isto venha nos ajudar a induzir que devemos começar a pensar em normatizar a utilização das duas técnicas. Desta maneira, poderemos melhorar a acuidade visual naqueles que tenham má qualidade refrativa e depois fazermos o crosslink para estabilização destas córneas. O crosslink como primeira escolha deveria ser utilizado apenas nas córneas que tenham boa qualidade refrativa. Mas, devemos sempre abrir um leque para novas tecnologias que vêm se despontando.

Poderia ser reduzida a necessidade de ceratoplastia penetrante em ceratocone. Dado a simplicidade da técnica e custos mínimos, isto também poderia ser bem apropriado para países em desenvolvimento. Porém, os resultados a longo prazo se fazem necessários para avaliar a duração do endurecimento e excluir efeitos colaterais.

\section{Abstract}

Objective: Postoperative corneal assessment after using two different types of crosslinking equipment Methods: Two groups of patients, group A with 36 eyes, and group B with 19 eyes, were submitted to the treatment for the stabilization of keractoconus by corneal collagen crosslinking. In group A the equipment used was Crosslink (IROC - Germany), while in group B the equipment was used was Xlink (Opto - Brazil).Results: Corneal reepithelization time, visual acuity, biomicroscopy, topography, corneal tomography and specular microscopy were assessed at 1 week, 1 month, 3 months, and 1 year after the surgical procedures. No significant differences were found in the assessment between the two groups. Conclusion: The postoperative results of both groups were similar.

Keywords: Keratoconus/surgery; Cross-linking reagents; Riboflavin; Ultraviolet rays; Collagen

\section{$\underline{\text { REFERÊNCIAS }}$}

1. Carlson AN. Keratoconus. Ophthalmology. 2009;116(10):2036-7.

2. Mahmood H, Venkateswaran RS, Daxer A. Implantation of a Complete Corneal Ring in an Intrastromal Pocket for Keratoconus. J Refract Surg. 2010; 25:1-6.

3. Ferrara P, Torquetti L. Clinical outcomes after implantation of a new intrastromal corneal ring with a 210-degree arc length. J Cataract Refract Surg. 2009;35(9):1604-8.

4. Cannon DJ, Foster CS. Collagen crosslinking in keratoconus. Invest Ophthalmol Vis Sci. 1978;17(1):63-5.

5. Goldich Y, Marcovich AL, Barkana Y, Avni I, Zadok D. Safety of Corneal Collagen Cross-linking With UV-A and Riboflavin in Progressive Keratoconus. Cornea. 2010 Feb 15. [Epub ahead of print]

6. Caporossi A, Mazzotta C, Baiocchi S, Caporossi T. Long-term Results of Riboflavin Ultraviolet A Corneal Collagen Crosslinking for Keratoconus in Italy: The Siena Eye Cross Study. Am J Ophthalmol. 2010 Feb 5. [Epub ahead of print]

7. Seiler T, Hafezi F. Corneal cross-linking-induced stromal demarcation line. Cornea. 2006;25(9):1057-9.

8. Wollensak G, Spoerl E, Wilsch M, Seiler T. Keratocyte apoptosis after corneal collagen cross-linking using riboflavin/UVA treatment. Cornea. 2004;23(1):43-9.

9. Wollensak G, Spoerl E, Wilsch M, Seiler T. Endothelial cell damage after riboflavin-ultraviolet-A treatment in the rabbit. J Cataract Refract Surg. 2003;29(9):1786-90.

10. Hafezi F, Kanellopoulos J, Wiltfang R, Seiler T. Corneal collagen crosslinking with riboflavin and ultraviolet $\mathrm{A}$ to treat induced keratectasia after laser in situ keratomileusis. J Cataract Refract Surg. 2007;33(12):2035-40.

11. Orucov F. No progression of keratoconus after LASIK. J Refract Surg. 2009;25(4):329; author reply 329-30. 
12. Spoerl E, Wollensak G, Seiler T. Increased resistance of crosslinked cornea against enzymatic digestion. Curr Eye Res. 2004;29(1):35-40.

13. Wollensak G, Spoerl E, Seiler T. Riboflavin/ultraviolet-a-induced collagen crosslinking for the treatment of keratoconus. Am J Ophthalmol. 2003;135(5):620-7.

14. Wollensak G, Sporl E, Seiler T. [Treatment of keratoconus by collagen cross linking]. Ophthalmologe. 2003;100(1):44-9. German.

15. Pérez-Santonja JJ, Artola A, Javaloy J, Alió JL, Abad JL. Microbial keratitis after corneal collagen crosslinking. J Cataract Refract Surg. 2009;35(6):1138-40.

16. Pollhammer M, Cursiefen C. Bacterial keratitis early after corneal crosslinking with riboflavin and ultraviolet-A. J Cataract Refract Surg. 2009;35(3):588-9.
17. Rama P, Di Matteo F, Matuska S, Paganoni G, Spinelli A. Acanthamoeba keratitis with perforation after corneal crosslinking and bandage contact lens use. J Cataract Refract Surg. 2009;35(4):788-91.

18. Constantin M, Corbu C. [Corneal collagen cross-linking--results in keratoconus]. Oftalmologia. 2009;53(1):85-8.

Endereço para correspondência:

Edna Motta Almodin

Rua Silva Jardim, $n^{\circ} 359$ - Centro

CEP 87013-000 - Maringá (PR), Brasil

Fax: (44) 3225-1168

e-mail: edna@hospitalprovisao.com.br 